Int. J. Electrochem. Sci., 12 (2017) 2125 - 2134

\title{
Biosynthesis of Pd Nanoparticle Using Onion Extract for Electrochemical Determination of Carbendazim
}

\author{
Dan Liu, Fengzhi Wu \\ Department of Horticulture, Northeast Agricultural University, Harbin 150030, China \\ *E-mail: fzwu2006@aliyun.com
}

doi: $10.20964 / 2017.03 .70$

Received: 19 December 2016 / Accepted: 28 January 2017 / Published: 12 February 2017

\begin{abstract}
Recently, nanomaterials through biosynthesis have attracted extensive attention, owing to their nontoxic approaches. Herein, an environmental-friendly chemical approach was proposed to photosynthesize palladium nanoparticles (Pd NPs) with the extract of onion. UV-Vis spectroscopy, FTIR, SEM and XRD were employed to analyze the bio-synthesized Pd NPs. According to SEM as well as dynamic light scattering instrument, the mean size of the bio-synthesized Pd NPs was measured to be $18.9 \mathrm{~nm}$. Furthermore, the bio-synthesized Pd NPs was used to modify the surface of the screenprinted electrode, which exhibited an outstanding electro-catalytic activity for the determination of carbendazim in soil.
\end{abstract}

Keywords: Pd NPs; Biosynthesis; Onion; Electrochemistry; Sensing; Carbendazim

\section{$\underline{\text { FULL TEXT }}$}

(C) 2017 The Authors. Published by ESG (www.electrochemsci.org). This article is an open access article distributed under the terms and conditions of the Creative Commons Attribution license (http://creativecommons.org/licenses/by/4.0/). 